\title{
The mutual interactions of redox species in magmas: the role of differentiation and volatile degassing
}

\author{
Roberto Moretti ${ }^{1,2}$ CHARles Le LOSQ ${ }^{1}$, DANIEL \\ NEUVILLE ${ }^{1}$
}

\footnotetext{
${ }^{1}$ Université de Paris, Institut de Physique du Globe de Paris, UMR 7154 CNRS, Paris, France

${ }^{2}$ Observatoire Volcanologique et Sismologique de Guadeloupe, Insitut de Physique du Globe de Paris, Gourbeyre, France
}

The properties of magmas are heavily affected by redox equilibria. These are not only sensitive to changes in intensive parameters, such as temperature and oxygen fugacity $\left(\mathrm{fO}_{2}\right)$, because extensive parameters (composition) have major effects. This compositional control, which includes the amphoteric behaviour of some components, demands the understanding of the link between redox, acid-base properties and structure. Nevertheless, a precise and coherent chemical "syntax" is required to write chemical exchanges in aluminosilicate melts, even though the distinction between solute and solvent becomes blurred in such systems. For this reason, speciation of elements with multiple oxidation state is not only complex, but it changes with the marked polymerization of the silicate framework that obtains from to most basic compositions to silica-rich terms. We show how in natural magmas redox interactions involving iron and sulphur species are heavily affected by differentiation. This includes degassing of the two major volatile components, water and carbon dioxide. A useful set of equations is presented to illustrate how to interpret observations on melt and gas phases 